\title{
Projetos de futuro de jovens mulheres inseridas na educação de jovens e adultos no Alto Sertão da Bahia
}

Maria de Fatima Pereira Carvalho ${ }^{1}$ Carmem Lúcia Eiterer ${ }^{2}$

\begin{abstract}
Resumo:
Este texto discute o tema juventude e escolarização com ênfase nos projetos de futuro de jovens mulheres inseridas na educação de jovens e adultos, concluintes da segunda etapa do ensino fundamental na rede pública de ensino de Guanambi (BA), no Alto Sertão da Bahia. Trata-se de um recorte dos dados produzidos no contexto de uma pesquisa qualitativa em que se realizou Grupos de Discussão e entrevistas semiestruturadas personalizadas. As reflexões apontam que as jovens mulheres da EJA não são quaisquer mulheres, mas sim mulheres jovens, pobres, em sua maioria negras, sertanejas e nordestinas, que vivenciam enfrentamentos para permanecer no processo de escolarização. Os resultados assinalam ainda que, para a maioria das jovens pesquisadas, a formação/escolarização está atrelada a melhorar sua posição no mundo do trabalho, ao desejo da conquista da casa própria, da autonomia e da independência, especialmente, à independência financeira. As vozes coletivas dessas jovens clamam por uma sociedade de igualdade de direitos no que se refere ao gênero, a etnia, a classe, ao território e a geração, pois são vítimas de uma sociedade machista, patriarcal, branca, eurocentrada, racista, discriminatória.
\end{abstract}

\section{Palavras-chave:}

Juventude. Escolarização. Projetos de vida.

\section{Future projects of young women in the education of youth and adults in Alto Sertão da Bahia}

\begin{abstract}
This text discusses the theme of youth and schooling with emphasis on the future projects of young women inserted in the education of youth and adults, who have concluded the second stage of primary education in the public school system of Guanambi (BA), in the Alto Sertão of Bahia. This is a cutout of data produced in the context of a qualitative research in which Discussion Groups and semi-structured personalized interviews were conducted. The reflections point out that the young women of EJA are not any women, but rather young, poor, mostly black, sertanejas and northeastern women, who experience
\end{abstract}

\footnotetext{
1 Doutoranda em Educação, Professora da Universidade do Estado da Bahia. E-mail: f13carvalho@hotmail.com. ORCID iD: http://orcid.org/0000-0003-2273-4809.

2 Doutora em Educação, Professora da Universidade Federal de Minas Gerais. E-mail: eiterercarmem@gmail.com. ORCID iD: http://orcid.org/0000-0002-6978-155X.
} 
confrontations to remain in the schooling process. The results also point out that, for most of the young women researched, training/schooling is linked to improving their position in the world of work, to the desire for self-home, autonomy and independence, especially financial independence. The collective voices of these young women call for a society of equal rights in terms of gender, ethnicity, class, territory, and generation, since they are victims of a macho, patriarchal, white, eurocentered, racist, discriminatory society.

Keywords: Youth. Schooling. Life projects.

\section{Proyectos de futuro de mujeres jóvenes en la educación de jóvenes y adultos en el Alto Sertão da Bahia}

Resumen: Este texto aborda el tema de la juventud y la escolarización, con énfasis en los proyectos de futuro de las jóvenes implicadas en la educación de jóvenes y adultos, que han terminado la segunda etapa de la educación primaria en el sistema escolar público de Guanambi (BA), en el Alto Sertão de Bahía. Se trata de un recorte de los datos producidos en el contexto de una encuesta cualitativa en la que se realizaron grupos de discusión y entrevistas personalizadas semiestructuradas. Las reflexiones señalan que las jóvenes de la EJA no son cualquier mujer, sino jóvenes, pobres, mayoritariamente negras, sertanejas y nordestinas, que viven enfrentamientos para permanecer en el proceso de escolarización. Los resultados también señalan que, para la mayoría de las jóvenes investigadas, la formación/escolarización está vinculada a la mejora de su posición en el mundo laboral, al deseo de tener un hogar propio, a la autonomía y a la independencia, sobre todo financiera. Las voces colectivas de estas jóvenes claman por una sociedad de igualdad de derechos en cuanto a género, etnia, clase, territorio y generación, ya que son víctimas de una sociedad machista, patriarcal, blanca, eurocentrada, racista y discriminatoria.

Palabras clave: Juventud. Enseñanza. Proyectos de vida.

\section{Introdução}

Este texto apresenta um recorte da pesquisa de Doutorado desenvolvida com jovens mulheres inseridas na EJA, no Alto Sertão da Bahia. Ele situa-se no entrelaçamento entre os temas geração, raça, origem com foco nos projetos de vida, buscando entender especificamente como a escolarização os atravessa.

Do ponto de vista metodológico, trata-se de uma pesquisa qualitativa, devido às características das questões e dos objetivos que norteiam o processo de investigação. Para a produção dos dados, foram mobilizados cinco grupos de discussão, sendo um em cada uma das escolas visitadas da rede pública de ensino de Guanambi (BA). Destes grupos participaram entre cinco a doze jovens mulheres concluintes da segunda etapa do ensino fundamental ${ }^{1}$ na EJA, no período de 2017 a 2020. Para a escrita deste texto, foram selecionados aqueles depoimentos cujas discussões e reflexões se aproximam dos objetivos do tema recortado.

Discorrer sobre o campo da juventude compreendendo esta como uma categoria social heterogênea, implica refletir sobre as especificidades de cada experiência juvenil. Neste caso, a categoria experiência é utilizada com base nas ideias de Dubet em Sociologia da Experiência, que a conceitua como uma noção que designa as condutas individuais e coletivas dominadas pela heterogeneidade dos seus princípios constitutivos e pela atividade dos indivíduos que devem construir o sentido das suas práticas no bojo desta heterogeneidade (DUBET, 1994). 
Para delimitar de quais juventudes estamos falando, traçamos o perfil a seguir, foram ouvidas 51 jovens na faixa etária entre 15 e 22 anos, sendo que 18 delas na época da pesquisa possuíam de um a três filhos, assim estamos falando também de uma juventude que conjuga a responsabilidade pela maternidade. Sendo que seis vivem no meio rural. Dezoito delas estavam vivendo uma relação conjugal no momento da pesquisa. O total de 48 se autodeclaram pardas e/ou pretas (negras), sendo apenas três brancas e 49 são empregadas no trabalho doméstico ou de cuidado.

Assim, esta pesquisa investiga a categoria projeto de vida ancorada nas especificidades e realidades dessas jovens mulheres que frequentam a EJA no interior da Bahia procurando conhecer quem são, quais os seus modos de ser e projetos de vida e, se a escolarização toma parte deles. Nesse sentido, entendemos que se destaca a dimensão social, configurando diversos contextos em que vivem as jovens as suas realidades.

\title{
Juventudes atravessadas por gênero, raça e origem
}

As discussões mais recentes acerca da categoria juventude tem caracterizado como um processo não estanque, nem unívoco ou homogêneo. Nesse sentido, há mais de uma década, Dayrell (2003, p. 42) já dizia que:

\begin{abstract}
Construir uma noção de juventude na perspectiva da diversidade implica, em primeiro lugar, considerá-la não mais presa a critérios rígidos, mas sim como parte de um processo de crescimento mais totalizante, que ganha contornos específicos no conjunto das experiências vivenciadas pelos indivíduos no seu contexto social. Significa não entender a juventude como uma etapa com um fim predeterminado, muito menos como um momento de preparação que será superado com o chegar da vida adulta.
\end{abstract}

Por isto, preferimos empregar no decorrer deste texto, o termo juventudes, no plural (PAIS, 1993), a fim de reforçar a ideia de heterogeneidade que esta categoria incorpora, pois quando se trata de juventudes, inúmeros fatores são postos em questão, e precisam ser considerados, tais como: quem são essas jovens mulheres? Onde elas vivem? Como vivem? Quais são as suas trajetórias e projetos de vida?

Para caracterizar as juventudes, se faz necessário escutá-las, e a partir de suas vozes, contextualizá-las (SILVA, 2018). Segundo as jovens mulheres do Alto do Sertão da Bahia, sujeitas desta pesquisa, ser jovem e, mais especificamente, ser jovem mulher, negra, pobre, nordestina, sertaneja é vivenciar situações diferentes de outros(as) muitos(as) jovens do país. O processo vivenciado na juventude é influenciado tanto pelo meio social concreto, como pelas trocas que esse meio proporciona ao jovem (DAYRELL, 2005a).

Assumem precocemente desde a infância a responsabilidade com tarefas domésticas, seja para auxiliar a mãe que trabalha fora de casa ou mesmo trabalhando no cuidado de crianças para auxiliar financeiramente nas despesas da casa. Estas e outras singularidades caracterizam um tipo de inserção no mundo do trabalho na juventude. O trabalho doméstico persiste em suas realidades, podendo ser conciliado com o trabalho no campo. "Trabalhei junto com o meu namorado na colheita de laranja em São Paulo, foi menos de um mês, mas deu para ganhar um dinheirinho" (Cacto, entrevista, dez. 2019).

Entre os processos de socialização e as vivências das juventudes encontramos os modos de relacionamentos construídos por meio das redes sociais, "conheci o meu atual namorado pelas redes sociais e quero me casar com ele" (Cacto, entrevista, dez. 2019). Nesse contexto, entendemos a categoria juventude, assim como as culturas juvenis, a partir da diversidade, considerando as interações sociais e simbólicas que poderão interferir nas trajetórias sociais construídas por essas jovens. 
A juventude é uma categoria dinâmica transformando-se na medida das mutações sociais que vêm ocorrendo ao longo da história. Na realidade, não há tanto uma juventude e sim jovens, enquanto sujeitos que a experimentam e sentem segundo determinado contexto sociocultural onde se inserem. (DAYRELL; NOGUEIRA; MIRANDA, 2011, p. 16).

Compartilhamos a perspectiva dos estudos ${ }^{2}$ e pesquisas referentes ao campo da juventude que reconhecem a diversidade de características que compõem essa fase da vida, cujo estudo extrapola as questões etárias. Nesse sentido, concordamos com Bastos (2009, p. 10) ao afirmar que,

O 'ser jovem' varia de acordo com a classe, o gênero, a raça, o local de moradia, por exemplo. Esses recortes sociais interferem nas possibilidades de inserção social dos sujeitos. A juventude, enquanto um conceito construído historicamente, recebe significados diversos de sociedade para sociedade, no tempo e no espaço, não podendo, desta forma, serem estabelecidos limites etários fixos para demarcar esse período de vida.

Para esta autora, considerando a juventude como grupo social, é preciso levar em conta que, ainda que compartilhando a mesma idade cronológica, os jovens partilham modelos culturais diferentes e se confrontam com problemas sociais específicos. Nesse sentido, ela afirma:

Juventude diz respeito a uma fase da vida constituída e significada pela sociedade em determinado tempo, espaço e momento histórico; jovens são os sujeitos sociais imersos nesta condição que ao longo de seu percurso de vida experimentam esta fase de diferentes formas a partir dos recortes de gênero, classe e raça, entre outros. (BASTOS, 2009, p. 41).

A nosso ver, as jovens mulheres que frequentam a EJA têm suas trajetórias assinaladas por essas situações em que ora uma aparente homogeneidade conferida à sua geração parece prevalecer e ora a heterogeneidade de suas condições de gênero, raça, classe e geração limitam seus percursos. Verificamos que essas jovens se inserem numa posição assimétrica em determinados grupos sociais, principalmente, por conta de sua classe e raça, tendo ainda que conviver com estigmas sobre o local de moradia, em se tratando daquelas jovens que residem no campo ou na periferia da cidade.

A vivência da juventude nas camadas populares tem se mostrado mais difícil, uma vez que a condição de ser jovem aliada à pobreza faz com que o principal desafio seja garantir a sobrevivência, numa tensão entre o prazer imediato e a tentativa de realização de um projeto de futuro (DAYRELL, 2007).

Em se tratando de jovens mulheres da EJA, do Alto Sertão da Bahia, a constatação dos atravessamentos identitários nos seus discursos, "ser jovem mulher já é difícil diante das tantas responsabilidades que temos que assumir para nos sustentar e ajudar a nossa família, o pior ainda, é ser negra e pobre" (GD 3, mar. 2019). Aquelas que frequentam a educação de jovens e adultos se encontram em situação de desprestígio social. Experimentam os processos desiguais de tornarem-se negras e mulheres numa arena de probabilidades na qual estão em jogo possibilidades e limites para configurarem seus projetos de vida, suas escolhas e suas trajetórias.

\section{Projetos de vida no horizonte possível}

Ao pensar em projetos de vida, não nos limitamos ao recorte temporal de um tempo futuro, seja próximo ou distante, mas abordaremos o tema na perspectiva da narrativa, que envolve passado,

2 As pesquisas referentes ao campo da juventude têm tratado essa categoria como tentativa de abarcar e reconhecer as múltiplas experiências juvenis. Para mais aprofundamento, ver Abramo (2005, 2007); Dayrell (2007); Mesquita (2009); Rodrigues (2013), dentre outros. 
presente e futuro. Assim, reiteramos a ideia de que "todo projeto, por meio da identificação de um futuro desejado e dos meios próprios para fazer com que aconteça, estabelece certo horizonte temporal no interior do qual evolui" (BOUTINET, 2002, p. 78). Consideramos também, que o conceito de projeto está relacionado ao conceito de tempo, conforme dizia Meneses (2000, p. 35), “o homem se faz na história” e para a compreensão dessa história, a dimensão temporal é indispensável.

Alves (2013) assinala que os sujeitos vão se constituindo biograficamente a partir de um movimento continuum de articulação entre passado, presente e futuro. Há mais de duas décadas, Velho (1994) definia a categoria "projeto de vida" como metamorfose, que se realiza como processo temporal a partir da memória que apresenta os meios de alcançar esse projeto, não o limitando a apenas aspirações. Para esse autor, a memória permite a visão retrospectiva, que embasa a condução do projeto. Para ele, o projeto é uma forma de comunicação, um instrumento de negociação da realidade, e servirá como maneira de expressar e articular interesses, aspirações e objetivos.

Também nesta direção Velho (2003) aponta: "São visões retrospectivas e prospectivas que situam o indivíduo, suas motivações e o significado de suas ações, dentro de uma conjuntura de vida, na sucessão das etapas de sua trajetória” (VELHO, 2003, p. 101).

Cezar destaca que (2014, p. 29), "ao tecer projetos de vida as pessoas tomam conta de sua própria vida e entram em contato com o risco de enfrentar a diversidade decorrente de possibilidades". Cezar (2014) acrescenta:

A discussão de projeto de vida se constitui em perspectiva de identificação e nas relações sociais entre os jovens. Na juventude, em especial, as noções de pertencimento e diferenciação se constituem em processos identitários fragmentados e discursos polissêmicos sobre si. (CEZAR, 2014, p. 38).

Já segundo Giddens (2002), a possibilidade de tecer projetos de vida responsabiliza o sujeito com a sua própria reflexividade e perpassa uma escolha que não se desvincula de um grupo ou contexto. Também nesta direção, Soares $(2002$, p. 76) contribui: “o projeto é, ao mesmo tempo, o momento que integra em seu interior a subjetividade e a objetividade e é, também, o momento que funde num mesmo todo, o futuro previsto e o passado recordado. Pelo projeto, se constrói para si um futuro desejado, esperado". Ao constituir seus projetos de vida, as jovens mulheres nordestinas e sertanejas na EJA os constroem a partir de "qual futuro desejado e esperado"?

Os discursos das jovens mulheres do Alto Sertão da Bahia demonstram a relação entre passado e futuro quando constatam que não querem passar por situações iguais às de suas mães. "Não quero passar pelo que a minha passou, sem estudo e sem emprego, vive cuidando de casa, marido e filhos" (GD 5, mar. 2019).

Segundo Dayrell (2005), um projeto de vida se concretiza a partir de duas variáveis. Uma diz respeito ao autoconhecimento da(o) jovem e a outra refere ao conhecimento da realidade, para o autor "quanto mais o(a) jovem conhece a realidade em que se insere, compreende o funcionamento da estrutura social com seus mecanismos de inclusão e exclusão e tem consciência dos limites e das possibilidades [...] maiores serão as suas possibilidades de elaborar e de implementar o seu projeto" (DAYRELL, 2005b, p. 42-43). Então, os projetos de vida seriam uma ação dos sujeitos para transformar as suas aspirações e ideais em objetivos possíveis de serem alcançados. A escola acaba influenciando nos projetos de futuro de muitos(as) jovens, conforme adverte Dayrell (2007), "os(as) jovens valorizam a escola como uma promessa futura" (p. 1122). Também os discursos das jovens mulheres do Alto Sertão da Bahia mostram a escola presente como auxiliar na construção dos planos de futuro. 
Eu quero fazer o curso técnico de perícia, quero formar no 3o ano e fazer o técnico. E depois eu quero fazer a faculdade para depois fazer a perícia. O meu plano de cursar uma faculdade é mesmo para ingressar na perícia. Quanto ao tempo... até eu formar vai levar três anos, eu estou no 9o, vou fazer 1o e 2o junto e 3o só. Daqui três anos eu formo e depois eu tento a faculdade. (Barriguda, entrevista, nov. 2019).

Ratificando essa ideia, Ficagna e Orth (2010) apontam que uma das funções da escola é despertar nos(as) alunos(as) a competência de compreenderem e atuarem no mundo em que vivem. Para esses autores, é imprescindível que a escola dê aos(às) alunos(as) informações e formação para que possam atuar ativamente na sociedade, organizando-se e defendendo seus interesses e da coletividade.

Pensar os projetos de vida elaborados por estas jovens mulheres, requer, no entanto, pensar que não se dão de forma solitária, irracional e nem tão pouco num único momento decisório. "Ao contrário, é um processo complexo, onde o tempo, as sensações, as experiências, os sentimentos e as necessidades cotidianas rearranjam seus contornos" (BRAGA, 2018, p. 191). Nesse sentido, concordamos com Velho (2003) que as experiências particulares produzem implicações e caminhos projetivos divergentes, a depender da trajetória de vida de cada uma. Cada uma aspira percorrer diferentes itinerários para chegar a "ser o alguém que deseja ser" a partir das suas próprias experiências. Para Velho (2003, p. 26),

Os projetos são elaborados e construídos em função de experiências socioculturais, de um código, de vivências e interações interpretadas [...] formula-se e é elaborado dentro de um campo de possibilidades, circunscrito histórica e culturalmente [...].

Em se tratando de jovens mulheres da EJA no interior do Estado da Bahia, partimos da compreensão de que os seus projetos de vida são construídos em função das experiências, vivências e interações interpessoais que elas estabelecem. Complementando essa ideia, Juncken (2005) assegura:

\begin{abstract}
Um projeto por mais particular que seja, tem de se basear em um nível de racionalidade cotidiana em que expectativas mínimas sejam alcançáveis, embora as emoções do sujeito também sejam matéria-prima que constituem o projeto. O projeto implica algum tipo de avaliação, uma estratégia para realizar certas metas, uma noção de tempo com etapas se encadeando. O projeto individual propriamente dito é construído por meio de uma ideia mais ou menos elaborada de uma história de vida. (JUNCKEN, 2005, p. 20).
\end{abstract}

Destacamos que os projetos de vida das jovens mulheres nordestinas da EJA, do Alto Sertão da Bahia, assim como de outros(as) jovens mudam e se transformam, são atravessados por contingenciamentos, estando sujeitos a determinações provenientes da ação de outros e da história. Então, para conhecer os projetos de vida destas jovens mulheres da EJA é preciso olhar para a realidade e especificidades dessas jovens, como o contexto em que elas se encontram inseridas irá influenciar na constituição de seus projetos de vida, a partir de suas experiências e vivências. O presente vivido e a vida cotidiana delas trazem, ao mesmo tempo, as marcas do passado e as possibilidades do futuro. Elas vivenciam especificidades que não são iguais para todos(as) os(as) jovens da mesma faixa etária. Por isso, só as vozes desses sujeitos poderão nos dizer quem são elas, quais os seus projetos e modos de vida.

No caso específico das jovens mulheres da EJA no Alto Sertão da Bahia, que elementos compõem os seus projetos de vida? Ressaltam acima de tudo, a aquisição de bens materiais, no caso delas especificamente a casa própria, o preparo profissional, que para elas significa alcançar melhores condições no mundo do trabalho, garantindo-lhes salário com benefícios sociais como a carteira assinada, férias, etc. 
O tema do casamento, por exemplo, faz parte, para algumas, dos seus projetos. "O meu namorado quer casar comigo e eu com ele. Queremos formar uma família juntos. Já tenho um filho e ele uma filha" (Cacto, entrevista, dez. 2019). A ideia de projetos de vida aqui trazida pauta-se na interpretação do modo como as jovens mulheres vivem e se posicionam diante do contexto e realidades em que estão inseridas e pensam ou não, sobre o futuro.

Segundo Pizzinato et al. (2016), projetos de vida e juventude são diretamente atravessados por discursos que sustentam papéis e possibilidades sociais a partir de indicadores como gênero e território.

Os papéis de mulher/homem são representados com traços fortemente tradicionais e os territórios urbano/rural possuem características dicotômicas, ainda que com certa crítica. Todavia, é importante destacar modificações e possibilidades de empoderamento das jovens quando estabelecem pontos de fuga do que seria esperado socialmente - a exemplo das possibilidades de escolha em relação à educação e casamento. (PIZZINATO et al., 2016, p. 481).

Concordamos com Silva (2018), ao apontar que uma das questões postas às juventudes está vinculada ao projeto de vida. "Existe um tensionamento social de que na juventude se inicie um processo de reflexão e organização, com vistas ao futuro" (SILVA, 2018, p. 66). Ainda para esta autora, o termo projeto de vida comumente está vinculado somente a aspectos ligados à preparação para o mundo do trabalho. Por isso, tem-se exigido dos e das jovens a escolha de uma profissão para toda a vida, que muitas vezes, equivocadamente, outros fatores referentes à vida dos e das jovens ficam "de fora" da construção desses projetos (SILVA, 2018, p. 67).

A ideia de projeto de vida remete a um plano de ação que um sujeito se propõe a realizar em relação a algum campo de sua vida (profissional, escolar, afetivo) em um arco temporal mais ou menos largo. Tais elaborações dependem sempre de uma gama de possibilidades dadas pelo contexto socioeconômico e cultural no qual cada jovem se encontra inserido(a) e que circunscreve suas experiências. (LEÃO; DAYRELL; REIS, 2011, p. 1071-1072).

Neste texto, atentamos para a relação dos projetos de vida aos contextos sociais em que as jovens mulheres da EJA estão inseridas. Como já dito anteriormente, as juventudes são heterogêneas e assinaladas por desigualdades. Para Silva (2018, p. 79), "a construção de projetos de vida precisa estar relacionada em consonância com o que é possível e para isso, ela deve ser protagonizada pelas jovens e estas precisam ter consciência de sua realidade". Além destes aspectos, como verificamos nas entrevistas, o tempo e o futuro são percebidos de modos diferentes ${ }^{3}$.

Dayrell, Leão e Reis (2011, p. 1071), afirmam que projeto de futuro remete a "uma ação do indivíduo de escolher um, dentre os futuros possíveis, transformando os desejos e as fantasias que lhe dão substâncias em objetivos passíveis de serem perseguidos, representando, assim, uma orientação, um rumo de vida”. Para Almeida e Leão (2018, p. 244), o projeto de futuro está ligado “à dimensão do 'sentido do agir', remete a um horizonte de ação que o próprio indivíduo projeta, em alguma esfera de sua vida, a realizar no tempo futuro, em um arco temporal mais ou menos largo". Pensando nas jovens mulheres da EJA, sujeitos desta pesquisa, ao construir os seus projetos de vida, que aspectos temporais são levados em consideração por elas?

3 Quiçá um dos maiores desafios quando pensamos na elaboração dos projetos de vida, seja compreendermos a relação que as juventudes têm com o tempo e o futuro, na medida em que "o modo de conceber e viver o tempo não é um dado natural, muito menos metafísico, mas uma dimensão sociocultural que vem se modificando com o suceder das gerações, de acordo com o contexto histórico e cultural de cada grupo social" (LEÃO; DAYRELL; REIS, 2011, p. 1072). 


\section{Entre sonhos e desejos: projetos de futuro de jovens mulheres sertanejas}

Entre os sonhos e os desejos das jovens mulheres do alto Sertão da Bahia inseridas na EJA, participantes desta pesquisa, estão presentes a escola, a família, o mundo do trabalho e a conquista da independência (autonomia), conforme elas mesmas atestam em seus depoimentos.

\section{Escola (continuidade dos estudos)}

Sobre os sonhos para o futuro, as jovens mulheres relatam o desejo de término dos estudos na modalidade EJA e no ensino profissionalizante, além do ingresso no ensino superior. A continuidade dos estudos está atrelada ao contexto em que vivem, por vezes, sem muita firmeza na proposição da concretização desses sonhos por conta do aspecto financeiro. "Eu quero muito ser veterinária. Quero um curso na área da saúde, fazer enfermagem... Medicina eu sei que não é para meu bico mesmo, um curso muito caro" (GD 3, mar. 2019).

Com ênfase na melhoria de condiçõos de vida e de trabalho, as jovens mulheres destacam sonhos vinculados à conclusão do ensino médio e, para algumas, a inserção na universidade.

Terminar os estudos à noite e consegui fazer uma faculdade na área de enfermagem. Essa área é mais fácil para arrumar um emprego por aqui. As pessoas daqui que formaram em enfermagem estão trabalhando nos postos. Então é um curso que é mais fácil conseguir um trabalho. (GD 5, mar. 2019).

Em seus projetos enunciados indicam o desejo de superação da sua atual condição socioeconômica. Assim, essas jovens anunciam o desejo entre projeto e sonho, de inserção no curso superior que lhes garanta a renda para uma vida mais confortável num curto período de tempo. "Daqui a 5 anos quero ter terminado a escola e está cursando a faculdade. Quero cursar medicina ou direito e ter a minha vida independente". Outra jovem diz: "quero terminar os estudos e fazer o curso de Sistema de UTI" " (GD 3, mar. 2019). Outra jovem afirma fincando os pés numa realidade mais próxima.

Eu quero fazer o $\mathrm{CPA}^{5}$, não vou mentir, quero terminar logo e fazer o curso de Perito, o curso técnico mesmo, eu soube que tem ele no $\mathrm{CEEP}^{6}$. Na verdade, eu nem sei se consigo, as pessoas dizem que o CPA é muito difícil, muitos conteúdos. É uma prova, você agenda, passa na papelaria pega os assuntos, são muitos assuntos, tem assunto que você nunca viu na vida. É muito assunto, você não tem noção. (GD 2, mar. 2019).

Nessa mesma direção, outra jovem desse mesmo GD relata:

Quero está formada, saí desta escola, concluir o ensino médio e está atuando na polícia. Quero ser Polícia Militar. Para ser PM tem que estudar muito. Pelo menos daqui a cinco anos quero está estudando para fazer o concurso da PM. O meu sonho é mais longo, seria para daqui a 10 anos... quero está formada para policial. (GD 2, mar. 2019).

\footnotetext{
4 Segundo a jovem, esse é um curso da área de computação.

5 Os exames supletivos são realizados no Estado da Bahia pelas Comissões Permanentes de Avaliação (CPA), autorizadas pelo Conselho Estadual de Educação (CEE). O funcionamento das Comissões também é regulamentado pela Resolução CEE no $138 / 2001$ e Portaria SEC no 12.235/2002. A idade mínima para realização dos exames segue as anunciadas na LDB: 15 anos para o ensino fundamental e 18 anos para o ensino médio. O candidato poderá se inscrever nos Centros de Educação de Jovens e Adultos e prestar os exames mensais: no máximo de 3 (três) componentes curriculares para o ensino fundamental e 4 (quatro) componentes curriculares para o ensino médio. Disponível em: http://escolas.educacao.ba.gov.br/exame-supletivo-cpa. Acesso em: 19 ago. 2019.

6 Centro Educacional de Educação Profissional.
} 
Fica evidente nos discursos das jovens mulheres diferentes modos de lidar com a sua realidade e o futuro próximo.

\section{Família (cuidados com os filhos)}

As falas das participantes desta pesquisa evidenciam principalmente, o aumento da responsabilidade das jovens destacando o papel da mãe no cuidado dos filhos. Corroborando Lopes e Soares (2011), a condição da maternidade denota a transição do papel infantil para o adulto, representando, assim, a perda de liberdade e o aumento da responsabilidade na vida de meninas adolescentes. $\mathrm{O}$ discurso das jovens evidencia também a responsabilidade pelo trabalho doméstico. Nessa direção, Guedes e Daros (2009) há mais de uma década já apontavam que o cuidado e a maternagem, ligados ao trabalho reprodutivo, tornam-se um aprisionamento para as mulheres, afastando-as de planos e sonhos que não contemplem esta forma tradicional de exercício do feminino. $\mathrm{O}$ fragmento a seguir revela uma face dessa situação. No caso de Cacto, o plano incluiria a possibilidade de casamento, mas esse plano entra em conflito com a sua realidade de maternidade.

O meu namorado atual quer casar comigo. Se eu me casar e for morar em São Paulo, o meu filho terá que ficar aqui, só que eu não deixo o meu filho não, estou sem saber o que faço, porque em primeiro lugar vem o meu filho, homem vem depois, não é? Só que o meu marido não tem como vir para cá, porque aqui não tem emprego, ele tem habilitação, estudou, já terminou os estudos, ele é formado (ensino médio). Aqui não tem emprego. (Cacto, entrevista, dez. 2019).

A realidade descrita acima se destaca dentre outras. Vemos diferentes depoimentos com relação a maternidade, como a seguir.

Daqui a 5 anos, não me imagino casada de novo, quero estar com os meus filhos, formada no curso que eu quero... queria muito o curso de perito médico, mas para ficar mais de 10 anos estudando... vou tentar fazer o técnico que dura dois anos [...]. Já fui muito falada por ter tido filho nova, se daqui a 5 anos eu tiver alguém na minha vida e, se aceitar eu do jeito que sou, mãe de 2 filhos, mas marido não está nos meus planos, hoje em dia. (GD 2, mar. 2019).

A partir de suas vivências não aconselham as outras adolescentes a mesma experiência. Por exemplo, o relato da jovem que foi mãe com 13 anos,

A experiência de ser mulher, jovem e mãe, foi uma experiência maravilhosa, o ruim que tive muitas complicações durante a gravidez, e são muitas preocupações na cabeça. Às vezes a experiência nos dar mais responsabilidade, às vezes nos torna mais infantil... engravidar com 12 anos e ser mãe aos 13 anos, acabou que o meu filho hoje com 8 anos me considera mais com irmã do que mãe, acabou que a nossa relação em casa foi mais para esse lado, a minha mãe quem assumiu a responsabilidade de mãe nossa. Então, eu não arrependi de ter tido o meu filho, não estou arrependida de ter sido mãe nova, mas não aconselharia as minhas amigas a engravidarem novinhas, como aconteceu comigo. (GD 4, mar. 2019).

Nesse mesmo GD, outra jovem relata uma situação semelhante de maternidade aos 13 anos, destacando a falta de maturidade (responsabilidade) e os riscos à vida envolvidos:

Eu também tive filho de 12 para 13 anos. Na verdade, não me arrependi. Mas hoje talvez seria mais fácil engravidar nessa idade, não teria tanta discriminação. Quando engravidei, era muita discriminação contra a mulher que engravidava novinha, a culpa era toda dela. 
Comecei a namorar muito cedo e engravidei, os meus pais não me aconselharam a engravidar. E hoje o meu filho me ver mais como irmã do que como mãe dele. Hoje não aconselharia meninas de 12 e 13 anos engravidarem, pois, criança não é um boneco, é preciso muita responsabilidade. Muita dedicação. E sem contar que corre risco de vida... tanto a menina quanto a criança. Sugerimos que as meninas engravidem a partir dos 20 ou 25 anos de idade, é preciso ter mais maturidade. (GD 4, mar. 2019).

Ainda sobre projetos de futuro, o tema do casamento, revela contradições e a condição de subalternização muitas vezes vivida pelas mulheres nesta relação. A maioria das jovens manifesta o desejo de não reproduzir em suas vidas situações como as vividas pelas próprias mães - o casamento e a dependência financeira do companheiro, o que leva algumas delas a negarem em seus projetos de futuro, a possibilidade do casamento: "casamento não faz parte dos nossos projetos, Deus nos livre disso, longe de mim o casamento" (GD4, mar. 2019). A maioria das jovens participantes deste estudo fez referência a ausência de intenção de vir a se casar, referem-se ao casamento de maneira negativa ou secundária para os seus projetos de futuro, destacando como prioridade a luta pela independência. "Daqui a 5 anos quero ter um trabalho, a minha casa, o meu carro, quero ser policial e não quero estar casada. Eu quero trabalhar e ajudar muitas pessoas, aquelas que mais precisam" (GD 3, mar. 2019).

Assim, a independência financeira, o carro e a casa própria, pelo menos a curto prazo, figuram como suas prioridades "casamento não é prioridade para mim, claro que penso em casar. Mas, primeiramente um emprego, uma casa, um carro, dar uma vida melhor para a minha mãe e meus irmãos" (GD 1, mar. 2019).

\section{Trabalho, independência e autonomia financeira}

Apresenta-se nos seus relatos a ambivalência entre a ideação de um projeto de futuro e sua concretização, a partir das experiências vivenciadas por elas, relacionadas à percepção de suas dificuldades e limites socioeconômicos. "Eu já quis ser tanta coisa... tentei ser cantora... não deu certo, tentei ser dançarina... também desisti. Daqui a cinco anos queria poder conhecer o mundo... o Brasil, a Bahia. Falta dinheiro, se conseguisse um trabalho melhor" (GD 2, mar. 2019).

Foi recorrente também nas verbalizações das jovens mulheres da EJA, participantes deste estudo o desejo pela independência num espaço temporal de 5 anos, "quero estar formada, com a minha família e minha vida arrumada, estar independente, ter o meu próprio lar, ou seja, ter as minhas coisas compradas com o meu próprio suor" (GD 2, mar. 2019). "Quero ter a minha casa própria, ser independente, independente em tudo mesmo". O tema da independência financeira é recorrente:

Ser independente, ter a minha própria casa. Não sei se vai dar tempo daqui a cinco anos... quero ser advogada... se não der tempo eu ser advogada, quero muito pelo menos já está cursando o curso de direito. Porque hoje em dia para a gente ser independente, a gente tem que trabalhar, não é? É preciso ter estudo, sem estudo a gente não é nada... Hoje a gente que ter pelo menos concluído o ensino médio, a gente tem que ter estudo, a gente tem que trabalhar, porque se a gente não tem estudo e nem trabalha, a gente nunca vai consegui ser independente, que é o que a gente mais quer: SER INDENPENDENTE. Mesmo que você seja independente, você tem a liberdade para decidir em casa, mas se não tem o dinheiro, você continua dependente dos outros. Se a gente quer alguma coisa, a gente precisa correr atrás. Então não adianta nada a gente querer ser independente se a gente não luta para isso. Eu mesma não queria estudar, queria trabalhar, ter o meu dinheiro, não gosto de pedir nada ao meu marido. Mas sentir a necessidade de estudar para conseguir algo melhor. A minha mãe que me ensinou a ser assim, não pedir nada aos outros, ter as nossas coisas com o nosso próprio trabalho, dinheiro do nosso próprio suor. (GD 2, mar. 2019). 
Melhorar a posição atual no mundo de trabalho faz parte dos projetos de futuro das jovens pesquisadas, conforme atesta de maneira concreta uma jovem (GD 3, mar. 2019), "quero um trabalho melhor, hoje trabalho na feira livre. Queria um trabalho na sombra e, se possível, no ar condicionado". Os relatos dessas jovens atrelam a melhoria das condições de vida a uma melhor condição de trabalho.

Ter concluído os estudos (ensino médio), possuir um emprego melhor, pois a doméstica e/ ou babá ganha muito pouco, metade de um salário mínimo... ter uma vida melhor... e dar uma vida melhor para os meus filhos.... Meu sonho é não depender de homem... Poder me sustentar e sustentar os meus filhos. (GD1, mar. 2019).

As jovens mulheres reiteram a importância da inserção da mulher no mundo do trabalho por questões financeiras, o seu sustento financeiro vincula-se a possibilidade da conquista da independência (autonomia). No entanto, ressaltando a relação entre solitude e independência uma jovem relatou:

Desde muito nova eu já fui independente, tive que me assumir desde muito cedo a vida... Eu fiquei aqui ouvindo vocês falarem que desejam ser independente... Não é fácil ser independente... não é uma vida só de flores... Eu mesma moro sozinha... chegar em casa e não encontrar ninguém, não poder conversar com ninguém ... Às vezes me cai uma solidão. (GD 2, mar. 2019).

Possuindo um solo comum de trajetórias escolares interrompidas, interceptadas por desafios como a gravidez na adolescência, relacionamentos abusivos, exploração de sua força de trabalho, dentre outras, as jovens mulheres da EJA nutrem múltiplos sonhos e desejos que oscilam entre a compra da casa própria à inserção na universidade. Então, para as participantes deste estudo, possuir a casa própria e inserir-se em melhores posições no mercado de trabalho, garantir a independência financeira, fazem parte dos projetos de futuro da maioria delas. Para muitas, "ter a casa própria para morar, um carro e concluir o ensino médio" (GD 1, mar. 2019), "queremos trabalhar e ter conforto, uma casa própria e ganhar o nosso próprio dinheiro” (GD 5, mar. 2019). O desejo de autonomia, de ser capaz de sustentar a si e aos seus filhos, sem depender da família ou dos pais deles e seus companheiros, é o projeto apresentado por elas para suas vidas daqui a cinco anos.

As jovens mulheres da EJA, participantes desta pesquisa, estabeleciam uma relação muito distante com a dimensão do projeto de futuro. Para elas, o tempo de cinco anos, por exemplo, parecia muito distante para projetar o futuro. Algumas até chegaram a negar a possibilidade de pensar sobre o seu futuro num temporal de cinco anos, e apontam a distinção entre projetos e sonhos. "Se continuarmos vivas daqui a cinco anos. Não sabemos se estaremos vivas" (GD 4, mar. 2019)

Não sabemos se daqui até lá teremos vida e saúde. Hoje em dia a gente não pode ficar fazendo muitos planos para o amanhã não, porque a gente não sabe o dia de amanhã. A gente planeja, eu tenho muitos planejamentos, mas o dia de amanhã eu não sei, eu sei o de hoje que eu estou vivendo agora. Eu não dou garantia para ninguém de nada. Como fazer projetos para o amanhã, e se eu morrer hoje? Você não vai sair debaixo de sete palmos do chão para vir realizar os seus projetos. Você pode até sonhar, mas nem sempre, pode realizar. (GD 3, mar. 2019).

Entretanto, podemos afirmar que a relação com o futuro, exposta pelas jovens, participantes desta pesquisa não é a sua negação, mas seus projetos e desejos se referem a aquisição da casa própria, um emprego que garanta vínculo formal, ajudar financeiramente a família, proporcionar uma boa escola para os seus filhos, dentre outros desejos, faziam parte dos sonhos dessas jovens mulheres da

7 A pesquisa de campo foi realizada no período pré-pandemia, em 2019. 
EJA. O relato delas ratifica essa afirmativa: "daqui a cinco anos já quero ter a minha casa própria, o meu trabalho, a minha profissão, sem precisar depender de ninguém” (GD 3, mar. 2019).

Assim sendo, para a maioria das jovens pesquisadas, a conquista da casa própria e a independência (autonomia financeira) atrelada à formação/escolarização e alcance de melhor posição no mundo do trabalho faziam parte das suas perspectivas de futuro. Para algumas delas, o casamento e filhos aparecem nos projetos de futuro, porém, ainda assim somente após a conquista do trabalho formal, conforme atesta uma jovem do GD 4: "daqui a cinco anos quero estar casada, com um filho(a), mas antes disso, quero trabalhar e ganhar o meu dinheiro" (mar. 2019). Nessa mesma direção, outra jovem diz: "eu sei que daqui a cinco anos eu vou ser dona de casa, mas quero muito está formada para dar ao meu filho, uma vida melhor" (mar. 2019).

\section{Algumas considerações}

Este estudo procurou conhecer os projetos de vida de jovens mulheres que frequentam a educação de jovens e adultos, verificando em que medida a escolarização toma parte deles.

Do ponto de vista metodológico, optamos pela pesquisa qualitativa devido às características da interrogação desse estudo e dos objetivos que o subsidiaram. Os procedimentos metodológicos constituíram-se em grupos de discussão e entrevistas semiestruturadas personalizadas com jovens mulheres da EJA concluintes da 2a etapa da educação básica, na rede pública de ensino de Guanambi.

Nesta pesquisa percebemos que indicadores como gênero, etnia, classe social, geração, território (local de moradia) e projetos de vida são diretamente atravessados por discursos que sustentam funções e possibilidades sociais. As funções da mulher/homem são representadas com traços fortemente tradicionais e historicamente construídos. Contudo, é importante destacar possibilidades de mudanças quando as jovens mulheres estabelecem pontos de saída do que seria determinado e ou esperado pela sociedade, como a probabilidade de escolha em relação ao casamento, por exemplo.

Quanto aos projetos de vida, para a maioria das jovens pesquisadas, a conquista da casa própria e a independência atrelada à formação/escolarização e inserção em melhores posições no mundo de trabalho fazem parte das suas perspectivas de futuro. Percebemos que seus projetos estão atrelados à melhoria das condições de vida experienciadas por elas, demonstram reiteradamente em seus relatos o desejo de romper com a condição de submissão e mesmo sofrimento vivida por suas mães.

Nos parece ainda que elas elaboram seus projetos de futuro pensando na vida familiar (mais especificamente, nos(as) filhos(as)) e no mundo do trabalho, este aparece como possibilidade de tornar-se independente e realizar seus sonhos e desejos, como o alcance da casa própria. O trabalho é o grande destaque que ora motiva a permanência das jovens no processo de escolarização, pela busca de inserção no mundo de trabalho e/ou melhoria das condições de trabalho, ora contribui para as interrupções no processo de escolarização.

A continuação dos estudos está acoplada à conquista da independência financeira. Ainda que nos depoimentos coletados referentes aos projetos se apresentassem de futuro dificuldades em relação a eles quando se tratava da continuidade dos estudos. Concluir o ensino fundamental e cursar o ensino profissionalizante seria um patamar suficiente para a maioria das jovens pesquisadas.

Nas condições juvenis como jovens mulheres, estudantes da EJA, nordestinas, sertanejas, pobres, negras, trabalhadoras em situação de emprego informal, algumas mães, não observamos nos seus discursos, lamentações pelas experiências vividas por elas. Ainda que relatem enfrentamentos. Na maioria das vezes, elas naturalizam as dificuldades como a ausência de direitos trabalhistas, a violência de gênero, a discriminação de gênero e racial, diante das condições a elas impostas pela sociedade. Entretanto, as vozes coletivas dessas jovens clamam por uma sociedade de igualdade de 
direitos no que se refere ao gênero, a etnia, a classe, território e geração, pois são vítimas de uma sociedade machista, patriarcal, eurocêntrica, branca, racista, discriminatória.

As formas de representação das jovens participantes desta pesquisa chamam a atenção para a necessidade de pesquisas que compreendam melhor as trajetórias, demandas e formas de viver de jovens mulheres inseridas na educação de jovens e adultos. Ressaltamos ainda a necessidade de pesquisas em que se interseccionam as questões abordadas neste estudo, principalmente se considerarmos a área da educação de jovens e adultos.

Finalmente, vale a pena indicar algumas recomendações enfocando a criação de políticas públicas que contemplem as especificidades das jovens mulheres sertanejas além de propor a inclusão interseccionalizada da categoria gênero na educação de jovens e adultos, no Alto Sertão da Bahia.

\section{Referências}

ABRAMO, Helena. Considerações sobre a tematização Social da Juventude no Brasil. In: Juventude e Contemporaneidade. Brasília, DF: UNESCO: MEC: ANPEd, 2007. p. 73-90.

ABRAMO, Helena Wendel. Condição Juvenil no Brasil contemporâneo. In: ABRAMO, Helena Wendel; BRANCO, Pedro Paulo Martoni (org.). Retratos da Juventude Brasileira. São Paulo: Fundação Perseu Abramo: Instituto Cidadania, 2005. p. 40-54.

ALMEIDA, Jorddana Rocha de; LEÃO, Geraldo. No "Fio da Navalha": Projetos de Futuro de Jovens em privação de liberdade. Revista da FAEEBA: educação e contemporaneidade, Salvador, v. 27, n. 53, p. 237-250, set./dez. 2018.

ALVES, Maria Zenaide. Ser Alguém na Vida. Condição juvenil e projetos de vida de jovens moradores de um município rural da microrregião de Governador Valadares-MG. 2013. Tese (Doutorado em Educação) - Programa de Pós-Graduação em Educação, Universidade Federal de Minas Gerais, Belo Horizonte, 2013.

BASTOS, Priscila da Cunha. Entre o quilombo e a cidade: trajetórias de individuação de jovens mulheres negras. 2009. Dissertação (Mestrado em Educação) - Programa de Pós-Graduação em Educação, Universidade Federal Fluminense, Niterói, 2009.

BOUTINET, Jean-Claude. Antropologia do projeto. Porto Alegre: Artmed, 2002.

BRAGA, José Ricardo Marques. Trajetórias tecidas entre as luzes da cidade e as veredas do sertão: jovens mulheres rurais, ensino superior e projetos de vida. 2018. Dissertação (Mestrado em Antropologia Social) - Programa de Pós-Graduação em Antropologia Social, Universidade Federal do Rio Grande do Norte, Natal, 2018.

CEZAR, Marcelo Moreira. Projeto de vida: um retrato da mulher no campo. 2014. Dissertação (Mestrado em Psicologia) - Programa de Pós-Graduação em Psicologia, Pontifícia Universidade Católica do Rio Grande do Sul, Porto Alegre, 2014.

DAYRELL, Juarez; LEÃO, Geraldo; REIS, Juliana. Juventude, projetos de vida e ensino médio. Eduação \& Sociedade, Campinas, v. 32, n. 117, p. 1067-1084, out./dez. 2011.

DAYRELL, Juarez; NOGUEIRA, Paulo Henrique de Queiroz; MIRANDA, Shirley Aparecida de. Os jovens de 15 a 17 anos: características e especificidades educativas. In: CORTI et al. Caderno de reflexões: jovens de 15 a 17 anos no Ensino Fundamental. Brasília, DF: Via comunicação: MEC/SEB, 2011. p. 13-61.

DAYRELL, Juarez. A escola "faz" as juventudes? Reflexões em torno da socialização juvenil. Educação \& Sociedade, Campinas, v. 28, n. 100, p. 1105-1128, out. 2007.

DAYRELL, Juarez. A música entra em cena: o rap e o funk na socialização da juventude. Belo Horizonte: UFMG, $2005 a$.

DAYRELL, Juarez. Por uma pedagogia da juventude. Onda Jovem, São Paulo, n. 1, p. 34-47, 2005b.

DAYRELL, Juarez. O jovem como sujeito social. Revista Brasileira de Educação, Rio de Janeiro, n. 24, p. 40-52, dez. 2003.

DUBET, François. Sociologia da Experiência. Lisboa: Instituto Piaget, 1994.

FICAGNA, Marisa Fracalossi; ORTH, Miguel Alfredo. Educação para um novo cidadão: construindo possibilidades ou relações entre a teoria e a prática. In: ANDREOLA, Balduino Antonio et al. (org.). Formação de educadores: da itinerância das universidades à escola itinerante. Ijuí: Ed. Unijuí, 2010. p. 246-262. 
GIDDENS, Anthony. Modernidade e Identidade. Rio de Janeiro: Zahar, 2002.

GUEDES, Olegna de Souza; DAROS, Michelli Aparecida. O cuidado como atribuição feminina: contribuições para um debate ético. Serviço social em revista, Londrina, v. 12, n. 1, p. 122-134, 2009.

JUNCKEN, Elaine. Jovens Pobres e a construção de projeto de vida. 2005. Dissertação (Mestrado em Psicologia) - Instituto de Psicologia, Universidade Federal do Rio de Janeiro, Rio de Janeiro, 2005.

LOPES, Marta Julia Marques; SOARES, Joannie dos Santos Fachinelli. Biografias de gravidez e maternidade na adolescência em assentamentos rurais no Rio Grande do Sul. Revista da escola de enfermagem da USP, São Paulo, v. 45, n. 4, p. 802-809, 2011.

MENESES, Adélia Bezerra. Desenho mágico: poesia e política em Chico Buarque. São Paulo: Ateliê Editorial, 2000.

MESQUITA, Marcos R. Identidade, Cultura e Política: Os Movimentos Estudantis na Contemporaneidade. Maceió: EDUFAL, 2009.

PAIS, José Machado. Culturas Juvenis. Lisboa: Imprensa Nacional Casa da Moeda, 1993.

PIZZINATO, Adolfo et al. Jovens mulheres do âmbito rural: gênero, projetos de vida e território em fotocomposições. Psicologia \& Sociedade, Recife, v. 28, n. 3, p. 473-483, set./dez. 2016. Disponível em: http://dx.doi.org/10.1590/ 1807-03102016v28n3p473. Acesso em: 20 jan. 2018.

RODRIGUES, Maria Natália Matias. Jovens mulheres rappers: reflexões sobre gênero e geração no movimento hip hop. 2013. Dissertação (Mestrado em Psicologia) - Programa de Pós-Graduação em Psicologia, Universidade Federal de Pernambuco, Recife, 2013.

SILVA, Priscila Klein da. Registros de um Sonho: Jovens Mulheres privadas de liberdade fotografando seus projetos de vida. 2018. Dissertação (Mestrado em Educação) - Programa de Pós-Graduação em Educação, Pontifícia Universidade Católica do Rio Grande do Sul, Porto Alegre, 2018.

SOARES, Dulce Helena Penna. A escolha profissional: do jovem ao adulto. São Paulo: Summus, 2002.

VELHO, Gilberto. Projeto e metamorfose. Antropologia das sociedades complexas. Rio de Janeiro: Jorge Zahar Editor, 2003.

VELHO, Gilberto. Projeto e metamorfose: antropologia das sociedades complexas. Rio de Janeiro: Jorge Zahar, 1994.

Data de submissão: 31/01/2021

Data de aceite: 13/02/2021 